\title{
Keeping our borders safe: The social stigma of nursing in managed isolation and quarantine border facilities during the COVID-19 pandemic
}

Isabel Jamieson ${ }^{1,2,4}, \mathrm{PhD}, \mathrm{RN}$, Senior Lecturer, Department of Health Practice; and School of Health Sciences

Cathy Andrew ${ }^{2}, \mathrm{PhD}, \mathrm{RN}$, Associate Professor, and Head of School, University of Canterbury, School of Health Sciences

Jacinda King², MN, RN, Nurse Manager Nursing Workforce, Nurse Coordinator Postgraduate Nursing Education

${ }^{1}$ Ara Institute of Canterbury, Christchurch, Aotearoa New Zealand

2University of Canterbury, Christchurch, Aotearoa New Zealand

${ }^{3}$ Canterbury DHB, Christchurch, Aotearoa New Zealand

${ }^{4}$ Corresponding Author: isabel.jamieson@ara.ac.nz

\section{Citation}

Jamieson, I., Andrew, C. \& King, J., (2021).

Keeping our borders safe: The social stigma of nursing in managed isolation and quarantine border facilities during the COVID-19

pandemic. Nursing Praxis in Aotearoa New

Zealand, 37(3), 53-61.

https://doi.org.10.36951/27034542.2021.035

\begin{abstract}
This article reports on a qualitative, single centre descriptive study on the experiences of nurses working in managed isolation and quarantine facilities (MIQFs) in Aotearoa New Zealand. Semi-structed interviews, via Zoom, took place with 14 registered nurses. The focus of this article is on the personal and social impacts on the nurses. The four themes discussed are: protecting the community while being a risk to the community; the barriers beyond the borders - social stigma; kept at distance - families and social connections; and a part of, but apart from, other health professionals. This study captures a unique moment in the history of Aotearoa New Zealand and highlights how the nurses' professional and personal lives were significantly impacted. Unlike other studies of nurses caring for COVID-19 patients, the MIQF nurses were caring for guests who were in isolation due to the Aotearoa New Zealand's government directive to protect the borders from people returning to the country. The study offers valuable lessons for employers, colleagues, and the wider community about the necessity of supporting nurses through times of a pandemic.
\end{abstract}

Keywords / Ngā kupu matua: COVID-19; border protection / te tiaki i ngā tomokanga; isolation and quarantine / te noho takitahi me te taratahi; stigma / ngā take whakamā; nurses / ngā tapuhi

\section{Te Reo Māori translation}

Te whakahaumaru i ō tātou tomokanga mai i tāwāhi: He take e whakamā ai te tangata i waenga i te pāpori, arā, te mahi tapuhi i ngā pūtahi noho takitahi me ngā whare taratahi i ngā tomokanga mai i tāwāhi, i wā o te mate urutā o COVID-19

\section{Ngā ariā matua}

Ko tā tēnei tuhinga he tāpae pūrongo mō tētahi rangahau kounga whakamārama pūtahi kotahi mō ngā wheako o ngā tapuhi mahi i roto i ngā whare noho takitahi me ngā whare taratahi (MIQF) i Aotearoa. I whakahaeretia ētahi uiuinga āhua ōkawa nei nā te Zoom, ki ētahi tapuhi rēhita, 14 huia katoatia. Ko te aronga nui o tēnei tuhinga ko ngā pānga whaiaro pānga pāpori hoki ki ngā tapuhi. E whā ngā tāhuhu i wetekina: ko te tiaki i te hapori i te wā o te mōrearea ki te hapori; ngā maioro kei tua atu i ngā tomokanga - ngā take whakamā i te hapori; te noho ki mamao - ngā whānau me ngā hononga ā-pāpori; me te noho hei wāhi, ahakoa tawhiti te noho, o ètahi atu rōpū kaimahi hauora ngaio. Ka hopukina ngā āhuatanga o tētahi wā motuhake i Aotearoa, i tēnei rangahau, hei konei ka kitea te pānga nui ki ngā oranga ngaio, whaiaro hoki o tēnei mea te tapuhi. He rerekē tēnei rangahau i ētahi atu rangahau mātai ki ngā mahi taurima a ngā tapuhi tiaki i ngā tūroro o COVID-19. I te taurima ngā tapuhi Whare Taratahi i ngā manuhiri noho takitahi, i raro anō i te whakahau a te kāwanatanga o Aotearoa kia tiakina ngā tomokanga 
i ētahi atu tāngata hoki mai ki tēnei motu. He nui ngā akoranga whai take mō ngā kaituku mahi, ngā hoa mahi me te hapori whānui, mō te hira o te tautoko i ā tātou tapuhi i ngā wā o te tētahi mate urutā.

\section{Introduction}

From January 30, 2020, COVID-19 became a notifiable disease in Aotearoa New Zealand (Jefferies et al., 2020) with confirmation of the first case in the country on 28 February 2020. By 11 March 2020, the World Health Organization declared COVID-19 a global pandemic. With many countries experiencing an exponential rise in infections and mortality rates, international borders rapidly closed. By 20 March 2020, the New Zealand government announced the closure of its borders to all but returning citizens, residents, close relatives, and approved essential workers and a nationwide lockdown came into force on 12 March 2020. All people entering Aotearoa New Zealand were required to stay in managed isolation and quarantine facilities (MIQFs) for at least 14 days. Those with a positive COVID-19 test were housed in designated quarantine areas where nurses were identified as the key health workers. By end January 2021 (the time of data collection for this study) there had been a total of 2,313 positive COVID-19 cases of which 594 had been at the border and stayed in MIQFs (Ministry of Health, 2021). This study describes the experiences of nurses working in MIQFs.

\section{Background}

The initial public health strategy in Aotearoa New Zealand was one of containment of the virus. As the lockdown progressed and new COVID cases diminished, the strategy shifted from containment to elimination. This was to be achieved and maintained through tight border controls and rigorous community surveillance including contact tracing. Initially, returning international travellers were required to self-isolate in the community however, on 9 April orders under the COVID-19 Public Health Response Act (2020) commissioned the use of New Zealand Defence Force facilities until empty tourist hotels were urgently converted into what became known as Managed Isolation and Quarantine

${ }^{1}$ The term "guests" is used throughout the article because that was the word used by the participants. It is important to note that MIQFs are not hospitals rather they are facilities that were established to quarantine people who
Facilities (MIQFs) (Jack \& Corich, 2021). All international travellers (guests ${ }^{1}$ ) arriving in the country required to isolate for at least 14 days in a managed isolation facility (Ministry of Business Innovation and Employment, 2020). Guests identified as having active COVID-19 were separated from others and relocated to a managed quarantine wing, with nurses as the key workers.

When the MIQFs were first established nurses were urgently employed via a recruitment agency. As the March 2020 lockdown extended, nurses working predominantly in perioperative and surgical areas where arranged surgery had been cancelled, were asked to volunteer for secondments to MIQFs. There were no specific operating procedures or protocols to guide them and very little orientation to the role. The processes were initially managed by the Ministry of Health however this transferred to Ministry of Business, Innovation and Employment (MBIE) in July. As Jack and Corich (2021) note, this was a context of urgency with sometimes only hours between a facility being stood up and the arrival of the first guests. Government agencies collaborated and worked together in processes of continuous quality improvement to tighten border controls and prevent the virus re-entering the community. New protocols and procedures evolved in response to incidents that occurred in the MIQFs, or at the borders, and as more data became available about the transmission and behaviour of the virus.

Nurses working in the MIQFs described their workload as relentless as they dealt with a high guest to nurse ratio and a countless number of problems for example, supporting people with escalating mental health issues; withdrawal from drug and alcohol; continuous rule changes; and supporting guests who were facing family crises and upset at the physical separation from their support networks (Longmore, 2021). Apart from routine COVID-19 testing nurses faced the challenges of dealing with stressed and often unwell guests at 'arm's length' due to the barriers of wearing full Personal Protective

were returning to Aotearoa New Zealand during a pandemic. 
Equipment (PPE) plus social distancing requirements set by the New Zealand government (Longmore, 2021; New Zealand Government, 2021).

Dealing with a global pandemic is not a new endeavour for nurses (Chan et al., 2005; Woods, 2016). Despite this, nurses have reported high levels of stress and stigmatisation. During the 2003 SARS pandemic $80 \%$ of nurses working in a Hong Kong hospital reported work-related stress due to the rapidly changing nature of the work, ongoing changes to infection control guidelines, heavy workloads, and the many uncertainties about the pathology of the disease. While $98 \%$ of nurses adhered to infection control measures $19 \%$ decided to self-isolate from family, friends, and the wider community which Chan et al. (2005) speculated added to a sense of social isolation.

Nurses caring for patients during a pandemic have been described as heroes fighting the enemy while simultaneously being stigmatised by the public (Khanal et al., 2020; Mauder et al., 2006; Mehta et al., 2021; Sadang, 2021). This stigma during the 2003 SARS outbreak extended to the nurses' families, with accounts of children being excluded from school and partners being sent home from work (Hall et al., 2003). Aotearoa New Zealand nurses working in MIQFs have also encountered this phenomenon (Longmore, 2021). Given this unprecedented situation the intention of this research was to uncover the experiences of the nurses working in the MIQFs so that these experiences, and the lessons learnt, could serve as a blueprint for the management of any future pandemics.

\section{Methods}

\section{Study design}

A qualitative descriptive approach, as described by Sandelowski, (2000) was used for this single centre study. This allowed for gathering information from participants in order to provide a "comprehensive summary of events in the everyday terms of those events" (Sandelowski, 2000, p. 334.)

\section{Ethics}

Ethics and locality approvals were given by the Ara Institute of Canterbury and the District Health Board (ref RO 20254).

\section{Sampling, recruitment and data collection}

Participants were recruited via purposive and snowballing sampling methods. Information about the study was sent to the work email addresses of all nurses working in the MIQF's. Those who were interviewed were encouraged to remind their colleagues about the study. Participants were interviewed by the second author (JK) via Zoom or face-to-face using a semi-structured interview. Consent was obtained prior to the interview. The interviews were conducted between mid-December 2020 and mid-January 2021 and lasted 35 to 85 minutes. Due to the rapidly evolving nature of isolation and quarantine requirements, in relation to the changing global and national context of the pandemic, the timing of the interviews reflects a snapshot of that particular time and the months preceding. Interviews occurred before vaccination became available in Aotearoa New Zealand.

Interviews were transcribed by an independent confidential transcription service or the interviewer. Transcripts were returned to those participants who indicated they wished to check for factual corrections or editing prior to inclusion in the data set. The transcripts were also anonymised and all distinguishing features removed.

\section{Data Analysis}

Data was analysed using the six-phase process for thematic analysis as described by Braun and Clarke (2006). Authors IJ and CA independently worked through the first three phases of familiarising themselves with the data; generating initial codes; and searching for themes before comparing findings. Phase four reviewing themes, and phase five defining themes were agreed collaboratively. All authors contributed to phase six; the draft and final reports. Trustworthiness of the study was implemented by applying the criteria of Lincoln and Guba (1985). This has been demonstrated through the use of the participants' verbatim words to link to themes, and the description of the data collection and analysis processes to demonstrate rigor. In addition to the checking and rechecking of the emergent themes and analysis by the three authors, the themes and draft findings were independently checked and verified by a nurse working in the MIQFs who was not involved in the study.

\section{Findings}

The 14 participants ranged in age from early 20 s to early 60s, included males and females, and nurses whose initial registration was New Zealand as well as those initially qualified overseas. Participants had 
been registered nurses for two months to over 40 years with a broad range of primary, secondary, and tertiary nursing experiences. Participants had worked in the MIQFs between five weeks and nine months. At the time of the interview most participants were still working in MIQFs with one returning to her original workplace from a secondment. Three had resigned or were no longer working in MIQFs.

Working in MIQFs had a significant impact on nurses. All participants recounted situations where they felt judged and ostracised by non-MIQF colleagues, friends, family members, and the community in general. Four themes emerged and are described in this section: Protecting the community while being a risk to the community; barriers beyond the borders social stigma; keeping distance and being kept at distance - families and social connections; and a part of but apart from other health professionals.

\section{Protecting the community while being a risk to the community}

Nurses were confronted with the paradox of being tasked with protecting the community from the virus, while being seen as a risk to the community due to their direct contact with guests returning to the country who were COVID-19 positive. Situations where there had been transmission between guests and community outbreaks were traced back via traditional public health contact tracing methods and genomic sequencing to identify the source of transmission from the MIQFs to the community. An unintended consequence of contact tracing for the nurses working in MIQFs was a sense that they were not altogether trusted by others to do their job correctly, and that they posed a risk rather than a protective function to the wider community. They felt blamed for the transmission of the disease when the transmission was often beyond their control such as MIQF ventilation systems being the vector and not their nursing practice:

People trust [non-MIQF nurses] to do their job. I think my hope would be that not only other health professionals but also the New Zealand public actually appreciate that. They need to maybe have a little bit more faith in us and our practice. [P12]

The systems were probably as good as they could be at the time, and we were safe going to work, and hence the community's safe and we're not a risk to the community. It was a shock to me to get to New Zealand [to work as a nurse] and get a sense that that wasn't really the understanding in the community. [P11]

Nurses were concerned at the way positive cases of COVID-19 were reported by the media. This led to a perception that the MIQFs were failing because they had positive cases. Nurses pointed out that positive cases identified then managed in MIQF was the strategy to prevent the virus infiltrating the community and this was not a failure of the system:

They talk about the numbers of COVID in the country every day or every third day or whatever it is now. Actually, it's not in the country, it's in managed isolation, so that's a good thing. Stop looking at it as a negative. Actually, you know what: it's working. So far, we're still not transmitting it through to the community. [P5]

The MIQF nurses accepted that although they were exposed to positive COVID cases returning from overseas, they were the frontline of preventing transmission to the wider community.

\section{The barriers beyond the borders: Social stigma}

Each of the participants recounted numerous examples of situations they or their colleagues encountered where their place of work and its associated stigma impacted their personal and social lives. They made adjustments in their lives to accommodate working in MIQFs. Personal friendships changed and they limited their social activities often due to the perceptions of others. Practices and policies of government agencies reinforced the message that MIQF workers were different to the rest of the community and, at times, placed restrictions on their wider movements:

Another thing that's making it quite difficult is
that the Ministry of Health have put out that
directive of not able to have second
employment. [P8]

Council buildings, they simply said, "Anyone who's working in MIQ is not allowed in here." [P14]

The nurses were confident in their use of PPE and the reduction of their personal risk in contracting the virus. The nature of their work in teams required that they cross check one another and were vigilant in 
identifying and correcting any momentary lapse including amongst the wider MIQF staff:

They [the public] don't understand how seriously we take it and how we manage it, what we do to keep ourselves safe at work....We've got rules and we know social distancing, we know hand hygiene, we know putting on and taking off of PPE. [P2]

I didn't get COVID. I'm not super-scared about it, cos I know that I'm doing the proper PPE. You won't get any COVID ifyou're wearing the proper one and you're wearing $N 95$ mask in the quarantine area. If you do your PPE well, then it's not scary. [P6]

Nurses can be required to self-isolate or be stood down from work for up to 14 days when identified as a close contact of an infected case or when there is a breach in PPE processes such as in a clinical emergency. Reconnecting with family and friends post-isolation can be challenging when others are concerned about ongoing risk:

I said to one person, "oh well come and have lunch" and she went, "No, you're working in isolation. I don't want to have anything to do with you." I was gutted. I'd spent two weeks in isolation [myself], not seeing anybody. [P9]

At times nurses went to quite extraordinary lengths to ensure that they did not personally become the vector for community spread. Nurses voluntarily undertook additional monitoring of their COVID-19 status in anticipation of social events and restricted their contact with friends and family. This vigilance increased at times of higher risk such as when they were working in areas where there were multiple COVID outbreaks amongst groups of guests within the MIQF:

I did decide that I was not going to see people outside of work for that period of time [during a COVID outbreak in a MIQF]. That means changing appointments; not seeing my parents, my brother with special needs. You do end up limiting what you do out of work. I don't think I even went to a supermarket during that time. [P5]

I'm very careful. I'll stay at home until I get my swab result on my day off, which is just a personal choice. [P13]
Despite this caution, interactions with others demonstrated that fear of catching the virus was widespread in the community. Nurses felt stigmatised and ostracised by the actions of family and friends including being excluded from celebrations and special events:

I invited my sister and her family over for a Christmas BBQ and she said she was sorry, but they wouldn't be able to come because her husband was very worried about COVID. [P3]

Mum said to me, "Just come to the back door and we'll cut you some cake." I said, "You're kidding me." She said, "It's because of nana, she's old." But she's not sick. They just didn't want me in there. [P4]

For the nurses, the impact of working in MIQFs extended beyond the workplace affecting their relationships and curtailing social and recreational activities. At times this had a marked personal impact but, despite this, most of the time the nurses made the necessary adaptations to their lives so that they could continue with their work.

\section{Kept at distance: Families and social connections}

Nurses identified that their family members and close contacts were sometimes the target of the fears and prejudices that they experienced themselves. Family members were made to feel they were a risk to the community because of their connection with a MIQF worker. Nurses described situations where workplaces and community organisations wanted reassurance or personal health information from their family members to prove that the nurse was not infected or was effectively monitored. When accessing healthcare, a link to a MIQF worker immediately raised the possibility that the family member may have the virus:

[The health professional] tried to pin the shortness of breath on me, like that I had COVID and I'd passed it on to my mum, despite my mum having this worsening shortness of breath over six weeks, and I get weekly tests. [P8]

On the rare occasion that a colleague tested positive for COVID, close contacts within the nursing team were stood down and required to self-isolate at home or in a quarantine facility. Family members of the close contact nurse were sometimes required to selfisolate resulting in situations such as family 
disruption, absence from work without pay, and missing study:

They wanted me to get them [children] out of uni and out of work and say you have to come home....They said, "Until you get a negative result, everybody's gotta stay home." [P9]

In some cases, the impact of self-isolation or discrimination towards family members was of such significance that it led to nurses discontinuing their work in MIQFs.

I never want to be in the situation of having to isolate when I am sole parent, again! [P3]

Some employers have sought reassurance that cohabitation with a MIQF nurse does not introduce risk to their workplace. Family members and flatmates have been asked to produce written evidence that the nurse is COVID free:

I've got a letter that I've given my husband to take to [his employer]. [P2]

I live in a flat with several other young working professionals and one got told not to come into work when they found out where I worked... Both of their employers were wanting proof of my latest swab. [P13]

In situations where a family member or flatmate was employed in the aged care sector, their formal conditions of employment reflected the deep concern that household contact with a MIQF nurse posed an unacceptable level of risk of virus spread to a vulnerable population:

In their contracts they [employer] don't want her [sister] to be near anyone who works in $M I Q[F]$. [P3]

The discrimination level is really bad.... since I was working in isolation they have stood her (flatmate) down from the aged care. She's paid though, which is good, but I felt guilty and she can't work anymore. I had to move out. [P6]

Nurses working in MIQFs had to balance how their place of work impacted not only on them personally but also on their significant others who are part of their social and support network outside work. Sometimes this situation became unsustainable, and they felt no alternative but to resign.

\section{A part of but apart from other health professionals}

The nurses described a number of challenging situations for them personally or when a family member needed to access healthcare. Many had incidents where they interacted with the health system and received responses from other health professionals that made them feel ostracised or unwelcome:

[The charge nurse told me] "Now we gonna have to deep clean this whole room." He just was nasty. He was saying that I was putting everyone at risk. [P8]

There was a sign that said if you worked in a managed isolation [you] had to gown up and put a mask on and all the rest of it and get shuffled into a separate room. [P10]

The reception I got [at a health service] was not only different but it was done at a volume that people around me in the waiting room, members of the public, could hear exactly what was being said. I could feel that people that were behind me actually were taking steps away from me. [P12]

Somewhat ironically, barriers put in place to minimise contact between the MIQF nurses and other nurses at employment related events meant that they were physically distanced for the event but free to mingle socially at breaks, lunchtime, and outside work:

[MIQF nurses] have to sit in a different room and Zoom it, which is crazy. Because then they go off and have morning tea and lunch together. Some of them live together. [P2]

When interacting with other health professionals for guest/patient related matters, MIQF nurses wear PPE. Despite this there is still a strong sense that they present a risk to other health workers:

The nurses who are receiving the patient have been the worst ... there's a lot a lot of fear and a lot of misinformation. [P7]

The boundary between work related and social activities became blurred. As is common in the wider community, social contacts are often those who have similar jobs and interests. For many MIQF nurses, their social networks include other nurses and health professionals. 
I've had some of my colleagues who go out with their normal group of friends for dinner or something, but no one will sit next to them. Generally, they're with other health professionals. [P5]

Nurses working in MIQFs did not expect to experience discriminatory behaviour from their colleagues in non-MIQF settings.

\section{Discussion}

Participants worked across six facilities in one geographical location and while they did not work in an austere setting, as noted by Talbot et al. (2021), they were undoubtedly working in an environment of uncertainty and constant change (Jack \& Corich, 2021). Unlike other studies of nurses caring for COVID-19 patients, the MIQF nurses were caring for guests who were in isolation due to the New Zealand's government directive to protect the borders from people returning to the country. While only some guests were COVID-19 positive, the MIQF nurses held a strong sense of responsibility to keep the community safe and COVID free. However, in doing so they have, at times, been stigmatised by friends, family, and other members of the health profession. The stigmatisation of nurses during times of a pandemic is not unprecedented. This phenomenon occurred during the HIV, Ebola, and SARS outbreaks (Hall et al., 2003; Kohi et al., 2010; Mauder et al., 2006;Wester \& Giesecke 2019) and elsewhere described during the COVID-19 pandemic (Khanal et al., 2020; Mehta et al., 2021; Sadang, 2021).

The experiences of the MIQF nurses were similar to the experiences of healthcare workers who cared for Ebola patients. Wester and Giesecke's (2019) qualitative study of Swedish healthcare workers caring for patients with Ebola during the Sierra Leone 2014 outbreak revealed that even though family and friends were not concerned about contracting Ebola from the healthcare workers upon their return home, they nonetheless exhibited stigmatising behaviour towards them. Some chose to sleep apart from their partner for a period of time; friends talked 'over the fence' rather than going into the healthcare workers home; friends' children were not allowed to visit; and work colleagues chose to use a separate lift. However, the healthcare workers in Wester and Giesecke's study (2019) only experienced this stigma for a brief period. This was attributed to the healthcare workers having returned from an outbreak occurring in another country. At the time when this study was conducted with the MIQF nurses their experiences of stigmatisation had been over approximately an eightmonth period and appeared to be ongoing given community concerns about the potential for widespread community outbreaks.

Other experiences captured in this study mirror those reported by Hall et al. (2003) such as the changed practice environment; the paradox of being a hero verses a villain; and the impact on immediate family who themselves were stigmatised because of their contact with an MIQF nurse. Yet the situation in Aotearoa New Zealand, at the time of writing, was vastly different. The nurses in this study were caring for guests, in a confined and contained environment, the vast majority of whom were COVID-19 free. However, this controlled environment coupled with the nurses abiding by strict PPE measures, adhering to social distancing and undertaking on-going personal swabbing to detect COVID-19 was not enough to allay the fears of the wider community.

The MIQF nurses' perceptions of Aotearoa New Zealand's media reporting is also of concern. During the SARS pandemic in Canada media accounts of nurses working with SARS patients fuelled their stigmatisation as well as contributing to their sense of being isolated from the community (Hall et al., 2003). In this instance nurses were concerned that they were being portrayed as failing in their role when positive cases were identified. This added a sense being isolated from the very community they were trying to protect. This concern was also evident in reported findings from a Canterbury District Health Board (CDHB) on-line survey of the well-being of 356 CDHB staff working in the MIQFs (Canterbury District Health Board, 2021).

\section{Strengths and limitations}

This study captured the experiences of nurses at a unique and unprecedented moment in Aotearoa New Zealand's history in the context of rapidly evolving systems and processes within MIQFs, and notably prior to the availability of a vaccine. Data were only collected from nurses working in one geographical location so no comparisons can be made with nurses working in MIQFs in other parts of the country. Nevertheless, although findings are not generalisable it is anticipated that the findings will resonate with other nurses working in the MIQF's as well as with their employers. 


\section{Recommendations}

Findings from this study provide information on the issues facing nurses working in MIQF and direction on the support required now and in future pandemic planning. Employers need to create a safe working environment whereby the nurses feel free to seek independent support and advice if needed, such as access to free counselling services. Furthermore, it is recommended that the employer provides nurses with a robust orientation program prior to working in a MIQF so that they are fully aware of the environment that they will be working in and how it differs to what might be expected in a clinical setting. It is also recommended that the wider community have access to information, via a reliable source such as MBIE, about the role of nurses working in the MIQFs to go some way to mitigating the public's concerns.

\section{Conclusion}

The working environment for nurses in the MIQFs is unique: it is not a clinical environment for patients seeking care, rather it is a facility adapted to protect the community by providing isolation and quarantine for people entering, or returning to, Aoteartoa New Zealand. Moreover, the complex and global nature of the pandemic, social media, conspiracy theorists, and anti-science commentaries, make it impossible to moderate and contradict misinformation that the nurses were subjected to. Therefore, it is imperative that colleagues, employers, and health professionals offer their support to the nurses working in MIQFs, enabling them to sustain this challenging role.

\section{References}

Braun, V., \& Clarke, V. U. (2006). Using thematic analysis in psychology Qualitative Research in Psychology, 3, 77-101. https://doi.org/10.1191/1478088706qp063oa

Canterbury District Health Board. (2021). Supporting the wellbeing of MIQ facility workers in Canterbury: Survey report and rapid literature review.

https://www.cdhb.health.nz/about-us/documentlibrary/supporting-the-wellbeing-of-miq-facilityworkers-in-canterbury/

Chan, S. S. C., Tiwari, A. F. Y., Leung, A. S. K., \& Wong, A. S. F. (2005). The impact of work-related risk on nurses during the SARS outbreak in Hong Kong. Family and Community Health, 28, 274-287.
Foley, E. L. (1918). Department of Public Health Nursing (the influenza pandemic of 1918-19). The American Journal of Nursing, 19, 189-195.

Hall, A. M., Angus, J., Peter, E., O'Brien-Pallas, L., Wunn, F., \& Donner, G. (2003). Media portrayal of nurses' perspectives and concerns in the SARS crisis in Toronto. Journal of Nursing Scholarship, 35, 211-216.

Jack, M., \& Corich, K. (2021). Rapid assessment of MIQ: Final report. Ministry of Business, Innovation and Employment. Wellington, New Zealand. https://www.miq.govt.nz/assets/MIQdocuments/rapid-assessment-miq-final-report.pdf

Jefferies, S., French, N., Gilkison, G., Graham, G., Hope, V., Marshall, J., McElnay, C., McNeill, A., Muellner, P., Paine, S., Prasad, N., Scott, J., Sherwood, J., Yang, L., \& Priest, P. (2020). COVID-19 in New Zealand and the impact of the national response: A descriptive epidemiological study. Lancet Public Health, 5, e612-e623. https://doi.org/10.1016/S2468-2667(20)30225-5

Khanal, P., Devkota, N., Dahal, M., Paudel, K., \& Joshi, D. (2020). Mental health impacts among health workers during COVID-19 in a low resource setting: a crosssectional survey from Nepal. Globalization and Health, 16(89), 1-12.

https://doi.org/https://doi.org/10.1186/s12992020-00621-z

Kohi, T.W., Portillo, C. J., Durrheim, K., Dlamini, P.S., Maloae, L. N., Greeff, M., Chirwa, M., Naido, J., Uys, L.R., \& William, l. (2010). Does perceived HIV stigma contribute to nurses' intent to migrate in five African countries? The Journal of the Association of Nurses in AIDS Care, 21, 134-143.

https://doi.org/10.1016/j.jana.2009.09.004

Lincoln, Y., \& Guba, E. (1985). Naturalistic Inquiry. Sage Publications.

Longmore, M. (2021). Nurses buckle under 'relentless' workload. Kai Tiaki Nursing New Zealand 27(1), 10-12.

Longmore, M., Manchester, A., \& O'Conner, T. (2020). Holding the line on COVID-19. Kai Tiaki Nursing New Zealand, 26(4), 14-15.

Mauder, G., Lancee, W., Balderson, K., Bennett, J., Borgundvaag, B., Evans, S., Fernandes, C., Gupta, M., Hunter, J., McGillis Hall, L., Nagle, L., Pain, C., Peczeniuk, S., Raymond, G., Read, N., Rourke, S., Steinberg, R., Stewart, T., VanDeVelde-Coke, S., ... \& Wasylenki, D. (2006). Long-term Psychological and Occupational Effects of Providing Hospital Healthcare during SARS Outbreak. Emerging Infectious Diseases 12, 1924-1932. https://doi.org/10.3201/eid1212.060584

Mehta, S., Machado, F., Kwizera, A., Papazian, L., Moss, M., Azoulay, E., \& Herridge, M. (2021). COVID-19: A heavy toll on health-care workers. The Lancet, 9, 226-228. https://doi.org/10.1016/S2213-2600(21)00068-0

Ministry of Business Innovation and Employment. (2020). COVID-19 Public Health Response (Managed Isolation and Quarantine Charges) Amendment Regulations 2020. Author.

https://www.mbie.govt.nz/dmsdocument/15140covid-19-public-health-response-managed-isolation- 
and-quarantine-charges-amendment-regulations2020-proactiverelease-pdf

Ministry of Health. (2021). COVID-19: Case demographics. Author. https://www.health.govt.nz/ourwork/diseases-and-conditions/covid-19-novelcoronavirus/covid-19-data-and-statistics/covid-19case-demographics\#case-details

New Zealand Doctor. (n.d.). Timeline - corona virus COVID 19. Author. https://www.nzdoctor.co.nz/timeline-coronavirus

New Zealand Government. (2021). Unite against Covid-19. Author. https://covid19.govt.nz/

Rice, G. (2018). 'That Terrible Time': Reflections on the 1918 Influenza Pandemic in New Zealand. New Zealand Medical Journal, 131(1481), 6-8.

Sadang, J. M. (2021). The Lived Experience of Filipino Nurses' Work in COVID-19 Quarantine Facilities: A Descriptive Phenomenological Study. Pacific Rim International Journal of Nursing Research, 25, 154-164.

Sandelowski, M. (2000). Focus on research methods: Whatever happened to qualitative description? Research in Nursing and Health, 23, 334-340. https://doi.org/doi:10.1002/1098-240X(200008)23

Shreffler, J., Petrey, J., \& Huecker, M. (2020). The impact of COVID-19 on healthcare worker wellness: A scoping review. Western Journal of Emergency Medicine, 21, 1059-1066. https://doi.org/10.5811/westjem.2020.7.48684

Summers, J., Baker, M. G., \& Wilson, N. (2018). New Zealand's experience of the 1918-19 influenza pandemic: A systematic review after 100 years. New Zealand Medical Journal, 131(1487), 54-69.
Talbot, L. A., Metter, E. J., \& King, H. (2021). History of the Military Nurse Corps and the 1918 Influenza Pandemic: Lessons for the 2019 Coronavirus Pandemic. Military Medicine 186(27), 27-32. https://doi:10.1093/milmed/usaa544

Wester, M., \& Giesecke, J. (2019). Ebola and healthcare worker stigma. Scandinavian Journal of Public Health. 47, 99-104. https://doi.org.doi:10.1177/140349817753450

Wood, P. J. (2016). Managing boundaries between professional and lay nursing following the influenza pandemic, 1918-1919: Insights for professional resilience today? Journal of Clinical Nursing, 26, 805812. https://doi.org/doi:10.1111/jocn.1357

\section{Acknowledgments}

We wish to thank the participants, and all MIQF nurses, who are protecting our borders to keep us safe and Lisa McKay, RN, who independently checked and verified the data analysis.

\section{Notes}

JK was involved in the employment of the nurses for MIQF hotels in Christchurch. She is no longer undertaking this role however, to safeguard the interests of the participants $\mathrm{JK}$ was not involved in data collection.

\section{Funding: None}

Conflict of interest: None 